\title{
Hourstonius wakabarae sp. nov. (Amphipoda, Amphilochidae) from the southeastern coast of Brazil
}

Fosca Pedini Pereira Leite and Silvana Gomes Leite Siqueira

(FPPL) Universidade Estadual de Campinas (UNICAMP), Instituto de Biologia, Departamento de Biologia Animal. Caixa Postal 6169, 13083-970, Campinas, São Paulo, Brazil, fosca@unicamp.br (SLS) Programa de Pós-Graduação em Ecologia, Instituto de Biologia, UNICAMP

\begin{abstract}
A new species of Hourstonius is described from the northern coast of São Paulo State. Hourstonius wakabarae sp. nov. is distinguished from the other species of the genus by the morphology and the size of the accessory flagellum of antenna 1, the articles of antennae 1 and 2, the mandibular molar, and the telson. The new species $H$. wakabarae lives associated with macroalgae growing on rocky shores, especially the brown alga Sargassum, at depths up to 2-3 m. This is the first species of the genus Hourstonius recorded from Brazilian waters.
\end{abstract}

Key words: Amphipoda, Amphilochidae, Hourstonius, Macroalgae, Taxonomy

\section{INTRODUCTION}

Amphipods occur widely over a diverse range of tropical, temperate and arctic intertidal and sublittoral habitats. The Amphilochidae are inquilines and commensals with sea fans, hydroids and other sessile marine invertebrates (Hoover and Bousfield, 2001) and are the smallest gammarids recorded living among the brown alga Sargassum (Leite, 1996; 2002). The family Amphilochidae was included in the superfamily Leucothoidea (Bousfield, 1979) and is composed of 15 genera and 70 species (Kim et al., 2010). Most of these species were described in the Northern Hemisphere, especially in the Pacific; only a minority of species are known from the Atlantic (Kim et al., 2010).

Two species of Amphilochidae, both belonging to the genus Amphilocus ( $A$. neapolitanus and $A$. schubarti) (Wakabara and Serejo, 1998) were recorded on the coast of Brazil. Amphilocus neapolitanus Della Valle, 1893 has been reported for São Paulo (Wakabara et al., 1983; 1991) and Rio de Janeiro (Serejo, 1998) and Amphilocus schubarti Schellenberg, 1938 for Pernambuco (Schellenberg, 1938). Hoover and Bousfield (2001) revised the family Amphilochidae based on a phyletic morphological analysis of species of the Pacific coast of North America, including five genera: Afrogitanopsis Karaman, 1980; Apolochus Hoover \& Bousfield, 2001; Gitana Boeck, 1871; Hourstonius Hoover \& Bousfield, 2001 and Paramphilochus Ishimaru \& Ikehara, 1986. They transferred many species of Amphilocus to Apolochus, and reclassified some species of Gitanopsis in the new genus Hourstonius. Hourstonius is separated from Gitanopsis Sars, 1895 by the presence of a distinct accessory flagellum, by the marginal robust setae on the mandibular molar, by the smooth posteroventral margins of coxae 2 to 4 , and by the more rounded apex of the telson (Kim et al., 2010). To date, 14 species of Hourstonius (Kim and Kim, 1992; Hirayama and Takeuchi, 1993; Hoover and Bousfield, 2001; Kim et al., 2010) have been described. This contribution describes Hourstonius wakabarae sp. nov. and presents the first record of the genus for the Brazilian coast. 


\section{Material and Methods}

The material examined was collected in the Ubatuba region on the northern coast of São Paulo, southeastern Brazil. Samples were taken at the Praia do Lamberto in 1997, and during the Biota - Marine Benthic Biodiversity (FAPESP) project in the autumn and spring of 2001 at Ilha dos Porcos Pequena (Picinguaba), both sites in the Ubatuba region.

The amphilochid species was associated with intertidal macroalgae, especially Sargassum sp., up to about 2-3 m deep. Samples of macroalgae were removed manually, using a spatula to scrape the rock. The amphipods were sorted under the stereomicroscope, and identified. Specimens were dissected under the stereomicroscope, and drawings were made with a camera lucida and digitally prepared with the software Inkscape 0.48 .4 , according to methods described by Coleman (2003). Appendages and mouthparts were dissected and mounted on glass slides with gelatinglycerol. The classification of crustacean spines and setae follows Watling (1989).

The material is deposited in the Crustacean Collection of the Museu de Zoologia of the Universidade Estadual de Campinas (UNICAMP) and preserved in $70 \%$ ethanol.

The following abbreviations are used in the figures: A, antenna; EP, epimeron; Gn, gnathopod; LL, lower lip; Md, mandible; Mx, maxilla; Mp, maxilliped; $\mathrm{P}$, pereopod; T, telson; UL, upper lip.

\section{RESULTS}

Order Amphipoda Latreille, 1816

Superfamily Leucothoidea Bousfield, 1979

Family Amphilochidae Boeck, 1871

Genus Hourstonius Hoover \& Bousfield, 2001

Genus diagnosis: Anterior head lobe generally rounded, accessory flagellum 1-segmented or minute. Upper lip notched, lobes asymmetrical; lower lip, inner marginal "notch" weak or lacking; mandible, molar distinct, outer triturating ridge with raised robust setae; maxilla 1 , palp slightly modified; maxilliped, palp segment 3 short; coxa 2, lower margin smooth (not serrate); gnathopods 1 and 2 strongly subchelate, propodus with paired robust setae at posterodistal angle demarcating palm; gnathopod 2, carpus narrow, posterior lobe elongate; epimeral plate 3, hind corner squared or rounded; telson triangular, medium to long apex broadly or sharply rounded (acute in $H$. japonica). Modified from Hoover and Bousfield (2001).

Type species: Gitanopsis vilordes J.L. Barnard, 1962

Genus composition and distribution: Genus is composed by 15 species: Hourstonius baciroa (J.L. Barnard, 1979) (Galapagos); $H$. breviculus (Hirayama, 1983 ) (Japan); H. geojeensis (Kim, Hendrycks \& Lee, 2010) (Korea); H. japonica (Hirayama, 1983) (Japan); $H$. laguna (McKinney, 1978) (Florida); H. longus (Hirayama, 1983) (Japan); H. magdai (Reid, 1951) (Tropical Atlantic); H. pele (J.L. Barnard, 1970) (Galapagos); H. pusilla (K.H. Barnard, 1916); H. pusilloides (Shoemaker, 1942) (South Africa); H. oozeki (Hirayama and Takeuchi, 1993) (Japan); H. robastodentes (Hirayama, 1983) (Japan); H. tortugae (Shoemaker, 1933) (Florida); H. vilordes (J.L. Barnard, 1962) (Alaska, Canada) and $H$. wakabarae sp. nov. (Brazil, present study).

\section{Hourstonius wakabarae sp. nov.}

(Figs. 1-4)

Material Examined: Holotype: 1 female, Praia do Lamberto, Ubatuba, São Paulo, Brazil, 2330’3”S, 4507’36”W, 4 September 1997, intertidal, ZUEC CRU 83. Paratypes: 1 female, Praia do Lamberto, Ubatuba, São Paulo, Brazil, 2330'3”S, 4507'36”W, 4 September 1997, intertidal, ZUEC CRU 82; 16 females, Praia do Lamberto, Ubatuba, São Paulo, Brazil, 2330’3”S, 4507’36”W, 4 September 1997, intertidal, ZUEC CRU 84; 1 female, Ilha dos Porcos Pequena, Picinguaba,

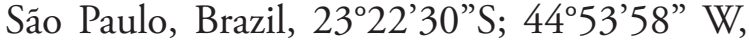
8 June 2001, subtidal, ZUEC CRU 81; 93 females, Ilha dos Porcos Pequena, Picinguaba, São Paulo, Brazil, 2322’30”S; 4453’58”W, 18 
October 2001, ZUEC CRU 82. All specimens collected among Sargassum growing on rocky shores; preserved in $70 \%$ ethanol.

Diagnosis: Antennae 1 and 2 subequal in length, antenna 1 with extended basal articles, flagellum articles with aesthetascs; accessory flagellum 1-segmented, similar in size to basal article 3; antenna 2 with articles 3 and 4 long; mandibular molar large, with ridged and toothed triturating surfaces, numerous setae of same size around external margin; gnathopod 1 subchelate, with carpus lobate and not reaching propodus distal margin, palm with regular and homogenous distribution of samesized setae; gnathopod 2 subchelate without robust setae on margin, with carpus lobate, reaching distal margin of propodus, palms of both gnathopods 1 and 2 with regular and homogeneous distribution of same-sized setae and 2 stout robust setae delimiting the palm. Telson triangular, entire, longer than wide, wider in proximal region, with rounded apex.

Description: Holotype female, body length $2.57 \mathrm{~mm}$. Head rounded; rostrum medium-sized and body shape similar to other members of genus. Antenna 1 slightly shorter than antenna 2. Peduncular article 2 larger than peduncular articles 1 and 3 (2.2: 4.7:3.1); flagellum with 13 articles. Each article bearing 1 or 2 long aesthetascs. Accessory flagellum 1-segmented, similar in size to first article of flagellum. Antenna 2: basal article 5 slightly longer than article 4, flagellum with 11 articles. Upper lip notched, lobes asymmetrical. Lower lip, lobes with apical concavity, with 2 small teeth and many fine setae on inner and outer distal margins. Mandible molar large and triturative, with numerous short robust setae that are similar in length and width. Spine row with 9 accessory blades on mandible, incisor normal and toothed, palp with 3 narrow articles of different lengths: article 1 short, article 2 similar in size to article 3 , which is lanceolate. Maxilla 1: inner plate rounded, with 1 terminal spine; outer plates with oblique distal edge bearing 8 robust setae; presence of 4 long slender bristles on inner edge; palp with 2 articles, distal article 2 times as long as basal, with 4 robust terminal setae of different sizes. Maxilla 2: inner plate with 6 medium to long robust terminal setae, outer plate longer than inner, with 4 medium to long robust terminal setae. Maxilliped: inner plate covered with numerous small bristles; with 2 distal facial and 1 terminal robust setae; outer plate setose, with serrate inner margin and 1 developed spine and several setae terminally; palp with 4 articles of different sizes, with numerous long slender bristles on anterior margins. Gnathopod 1: subchelate; coxa irregularly quadrate, with marginal setae; basis elongated, with 4 posteromarginal robust setae; merus with 4 posterodistal and 1 medial robust setae; carpus with spiny posterior lobe reaching $2 / 3$ along hind margin of propodus; palm transverse, corner defined by 2 stout robust setae; inner margin of dactyl proximally serrate. Gnathopod 2: subchelate, with elongated, narrow posterior lobe; coxa subrectangular with few small marginal setae; basis elongated, with 8 posteromarginal setae; distal edge of merus with 4 long setae and 1 short robust seta; carpus with elongated posterior lobe reaching edge of palm as far as hind margin of propodus; propodus distally expanded, with transverse serrate palm (bearing row of minute robust setae), corner defined by 2 stout robust setae and a short marginal distal lobe; dactyl inner margin serrate on upper half. Pereopod 3: coxal plate rectangular, longer than wide; with few small robust setae on anteroposterior margin; articles sparsely setose; dactyl long. Pereopod 4: coxal plate much larger than

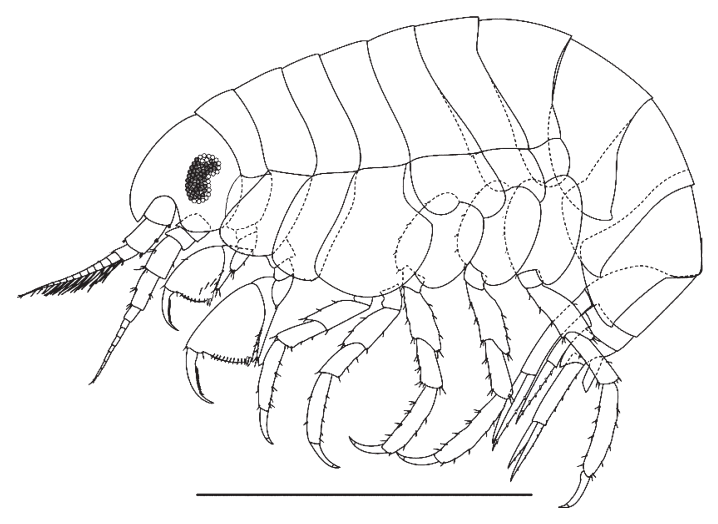

Figure 1. Hourstonius wakabarae sp. nov., female, $2.57 \mathrm{~mm}$ long (lateral view), Praia do Lamberto, Ubatuba region, São Paulo State, Brazil. Scale bar: $1.00 \mathrm{~mm}$. 


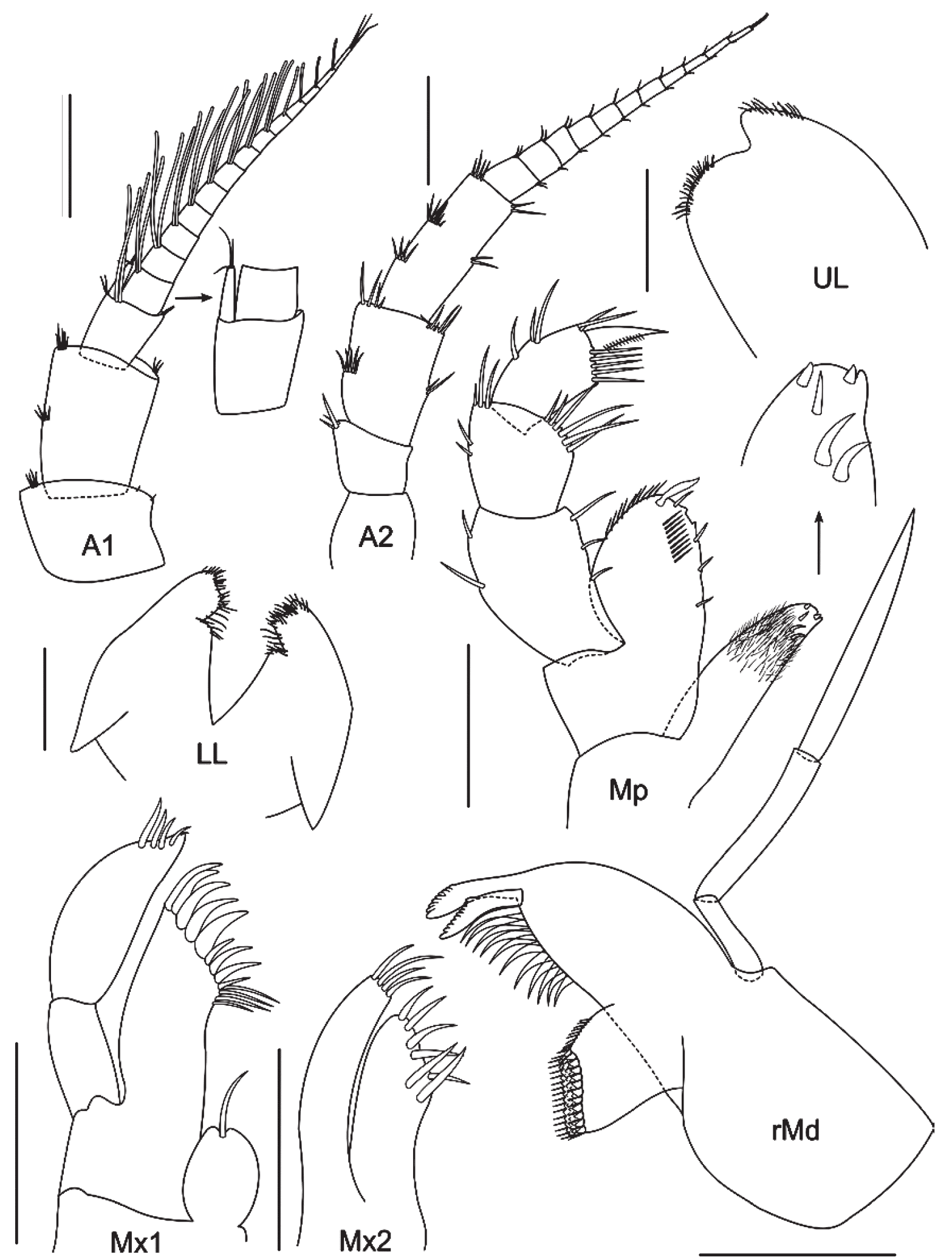

Figure 2. Hourstonius wakabarae sp. nov., female, $2.57 \mathrm{~mm}$ long. Praia do Lamberto, Ubatuba region, São Paulo State, Brazil. Scale bars: $0.1 \mathrm{~mm}$. 


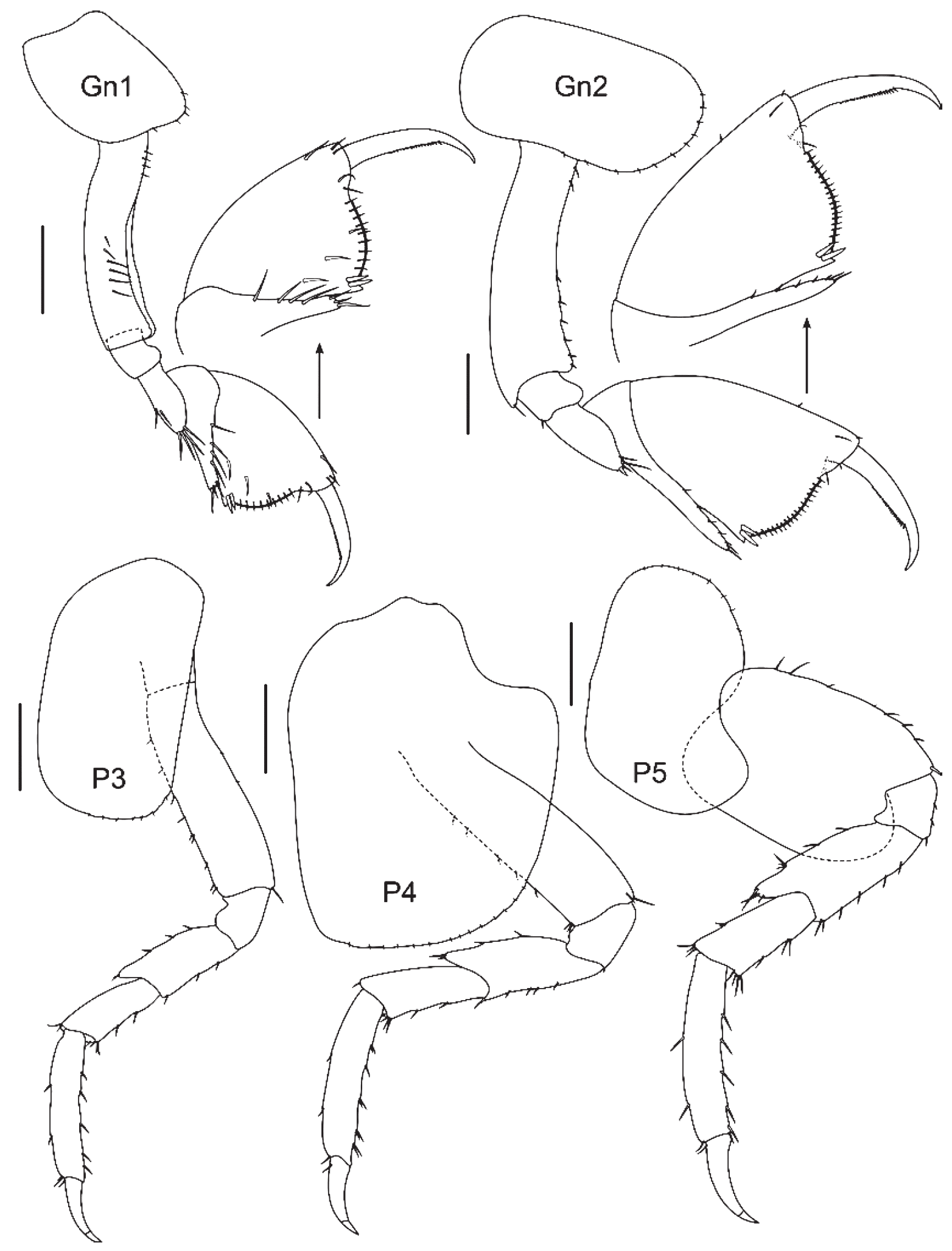

Figure 3. Hourstonius wakabarae sp. nov., female $2.57 \mathrm{~mm}$ long. Praia do Lamberto, Ubatuba region, São Paulo State, Brazil. Scale bars: $0.1 \mathrm{~mm}$. 


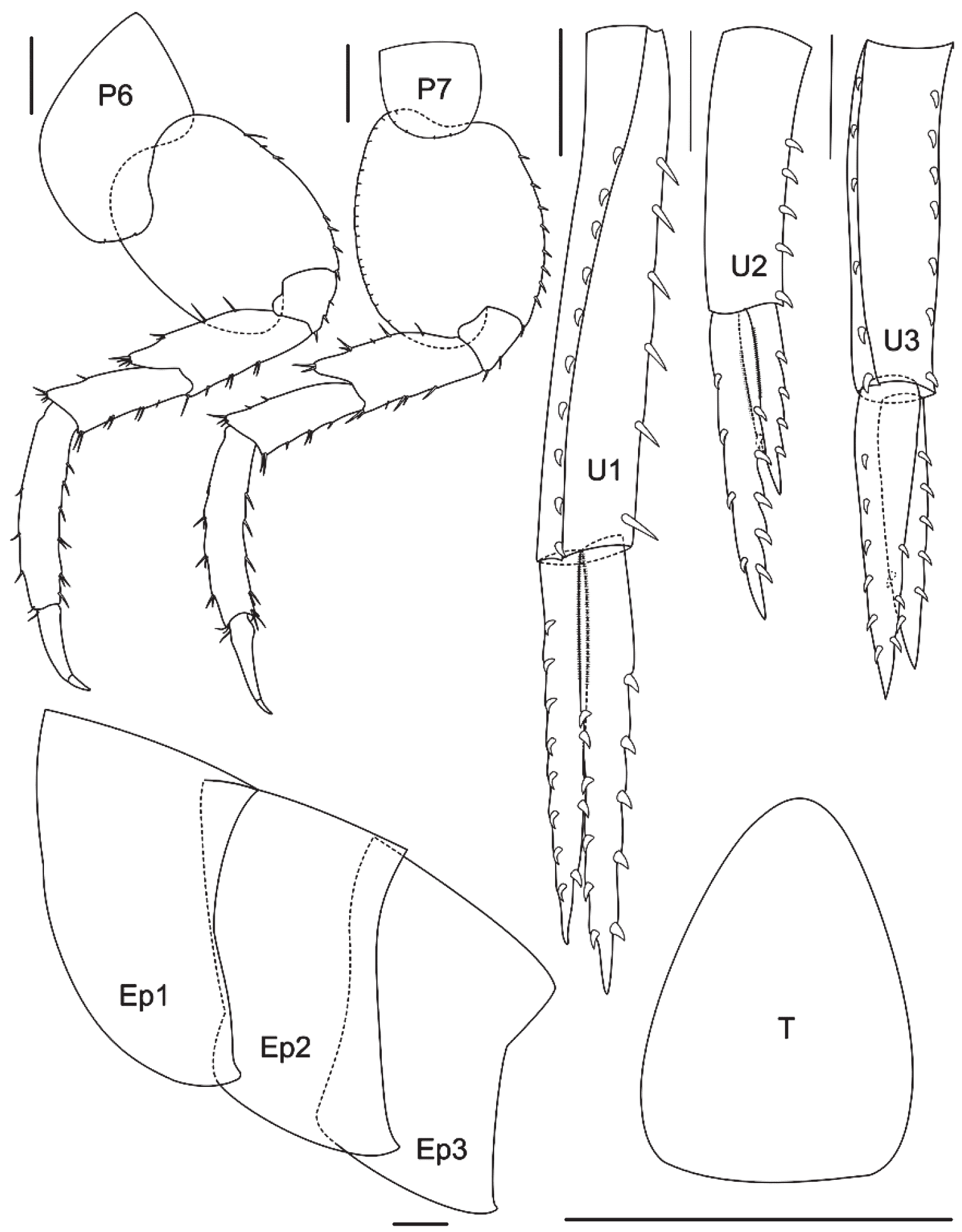

Figure 4. Hourstonius wakabarae sp. nov., female, $2.57 \mathrm{~mm}$ long. Praia do Lamberto, Ubatuba region, São Paulo State, Brazil. Scale bars: $0.1 \mathrm{~mm}$. 
preceding coxa, posterior margin excavate; otherwise as pereopod 3. Pereopod 5: coxal plate wider than long, posterolobate, basis expanded, with anteromarginal robust setae; ischium, merus, carpus and propodus with robust setae on each margin, dactyl long and slender. Pereopod 6: coxal plate wider than long, with expanded posterior lobe shorter than posterior lobe of pereopod 5; basis expanded, with anteromarginal robust setae, ischium, merus, carpus and propodus each with 1 anteromarginal robust seta, dactyl long and slender. Pereopod 7: slightly longer than pereopod 6, coxal plate small and narrowly oval, otherwise similar to pereopod 6 . Epimeron: corners of plates slightly produced, ventral margins bare. Uropod 1: extending beyond peduncle of uropod 3, peduncle longer than rami; with two rows of numerous robust setae $(10+6)$, rami lanceolate, outer ramus slightly shorter than inner ramus, outer ramus with 8 outer and 3 inner robust marginal setae; inner ramus with 5 inner and 5 outer robust marginal setae; opposing margins of rami setulose. Uropod 2: peduncle shorter than peduncles of uropods 1 and 3, with 4 robust setae, outer ramus $2 / 3$ as long as inner ramus, with 4 outer and 5 inner robust marginal setae; inner ramus with 2 inner marginal and 4 outer marginal robust setae; opposing margins of rami setulose. Uropod 3: peduncle elongate, shorter than uropod 1, with two rows of robust setae $(6+7)$; outer ramus slightly shorter than inner ramus, each margin with $6+3$ robust setae, inner ramus with $6+3$ robust setae on each side; opposing margins of rami setulose. Telson: triangular, entire, longer than wide, with enlarged distal margin and rounded apex.

Oostegites: spatulate, with few smooth setae of medium length. Brood plates rounded and enlarged in distal portion.

Males: Similar to the females in both size and morphological features.

Etymology: This species is named in honor of the late Dr. Yoko Wakabara, in appreciation of her great contribution to the knowledge of the amphipod fauna of Brazil.

\section{Discussion}

The family Amphilochidae was revised and included in the superfamily Leucothoidea (Bousfield, 1979). Hoover and Bousfield (2001) carried out a reorganization of the family and genera. Several species of Gitanopsis were transferred to Hourstonius, which was distinguished by having the mandibular molar large, with marginal fringe of slender spines (Hoover and Bousfeld, 2001). The genus Gitanopsis (sens. str.) was maintained, including species with distributions restricted to the Arctic and North Atlantic. Some previously described species of Amphilocus were transferred to Apolochus, which has a vestigial mandible molar. There are no records of Hourstonius for the Brazilian coast, but Apolochus neapolitanus (treated as Amphilocus) and Amphilocus schubarti were previously recorded for São Paulo and Pernambuco respectively (Wakabara and Serejo, 1998). The two species are morphologically similar to $H$. wakabarae except for details of the mandible, and these records may represent misidentifications. The mandible, a diagnostic character, is not included in the original description of Della Valle (1893). Unfortunately, the material is no longer available for inspection.

Most species of the genus Hourstonius are from North Pacific waters, including the coasts of Japan, Hawaii, Korea, California, Alaska and Canada: H. vilordes (J.L. Barnard, 1962); H. breviculus (Hirayama, 1983); H. japonica (Hirayama, 1983); H. longus (Hirayama, 1983); H. robastodentes (Hirayama, 1983); H. laguna (McKinney, 1978); H. pele (J.L. Barnard, 1970); H. baciroa (J.L. Barnard, 1979); H. magdai (Reid, 1951); H. oozeki (Hirayama \& Takeuchi, 1993); H. geojeensis (Kim, Hendrycks \& Lee, 2010); and $H$. pusilloides (Shoemaker, 1942). Hourstonius pusilla (K.H. Barnard, 1916) is from South Africa. Also, two species are described for the western Atlantic region: H. laguna McKinney, 1978, found in the Gulf of Mexico, Bermuda and the Caribbean; and $H$. tortugae Shoemaker, 1933 , from the coast of Florida. 
Hourstonius wakabarae sp. nov. differs from other known members of Hourstonius in the size and shape of the eyes, the presence and size of the 1-segmented accessory flagellum, the morphology and shape of the mandible molar and coxa 1, the length of the carpal lobe of subchelate gnathopod 2, and the size and morphology of the telson (Tab. 1). Also other characteristics were utilized to separate the species, such as the size of the gnathopod 2 propodus, the presence of a tooth on the pereopod dactyls, and the number of setae on several appendages.

In summary, $H$. wakabarae can be distinguished from $H$. pele by the shape and size of the carpal lobe and of the propodus of gnathopod 2. Hourstonius pele has a carpal lobe shorter than the ventral margin of the propodus and a slightly expanded propodus, distally broad and about 75 to 85 percent longer than that of $H$. wakabarae.

The new species differs from $H$. baciroa by the shape of the molar of the mandible. Hourstonius wakabarae has a triturative mandible molar, with numerous short setae that are similar in length and width; while the molar of $H$. baciroa is cylindrical and slightly triturative. Hourstonius vilordes has the coxa 1 quadrate, as well as the presence of two robust setae on the anterior margin of the propodus of gnathopod 2; it also has a pair of small setae on both proximal margins of the telson. In contrast, $H$. wakabarae has the telson without setae and lacks robust setae on the anterior margin of gnathopod 2. Hourstonius robastodentes has the telson with a pair of small setae on both proximal margins, while the telson of $H$. wakabarae lacks setae.

Hourstonius japonica and $H$. longus both have the telson with an acute apex telson, whereas in $H$. wakabarae the apex of the telson is rounded. Hourstonius geojeensis has a tooth on the inner margin of the pereopod 3-7 dactyls, whereas such teeth are not present in $H$. wakabarae. In $H$. breviculus the antennae 1 and 2 are smaller than those of $H$. wakabarae. Another character that distinguishes the two species is the morphology and size of the lobal carpus, which is stout with a blunt attenuate apex that does not reach the palmar spines in $H$. breviculus; whereas the posterodistal extension of the carpus reaches the palmar spines in $H$. wakabarae.

Hourstonius magdai has the propodus of gnathopod 2 strongly dilated distally, whereas that of $H$. wakabarae is not as developed. Also the carpal extension of gnathopod 2 of H. magdai is shorter than the corresponding structure of $H$. wakabarae (about $2 / 3$ of the margin). Hourstonius pusilloides has the gnathopod 2 carpal lobe very short, whereas the carpal lobe of gnathopod 2 of $H$. wakabarae is the same size as the ventral margin of the propodus.

Hourstonius laguna differs from $H$. wakabarae in having more slender articles of the peduncle of antenna 1 and in the length of the carpal lobe of gnathopod 2, which is shorter than that of $H$. wakabarae (about $2 / 3$ of the margin). Another noticeable difference was observed in the crusher molar of the mandible. The mandible molar of $H$. wakabarae has many short setae of equal size on its margin, and numerous setae on the lateral margin. The crusher molar of the mandible of $H$. laguna has scattered, longer robust setae on its margin. Hourstonius tortugae has a short ovoid telson, less than twice as long as broad and obtuse distally; whereas $H$. wakabarae has an elongate, linguiform telson. Also, the two species show differences in the eye morphology: round and small in $H$. tortugae and reniform in $H$. wakabarae.

Ecological information: Species of Hourstorius are part of the fauna associated with biological substrates such as macroalgae, sponges and reefs. Also, they are present in shallow depths (Ortiz et al., 2007) and in low-energy environments such as mangroves, marine sinkholes, and caves (Baldinger et al., 2002). Hourstonius wakabarae sp. nov. was collected among macroalgae on an intertidal rocky shore and in shallow depths $(2-3 \mathrm{~m})$, usually associated with algae of the genus Sargassum, on the northern coast of São Paulo. 
Table 1. Diagnostic characters of Hourstonius wakabarae sp. nov. and similar species. (*from Kim et al. 2010. Abbreviations: U2 Uropod 2; U3 - Uropod 3)

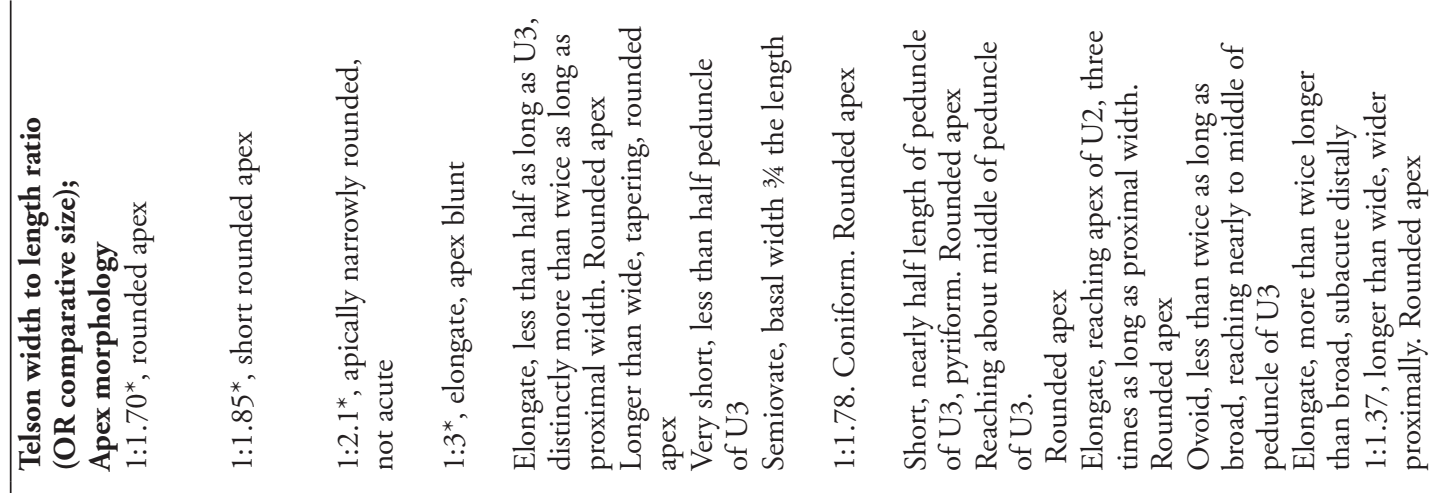

S

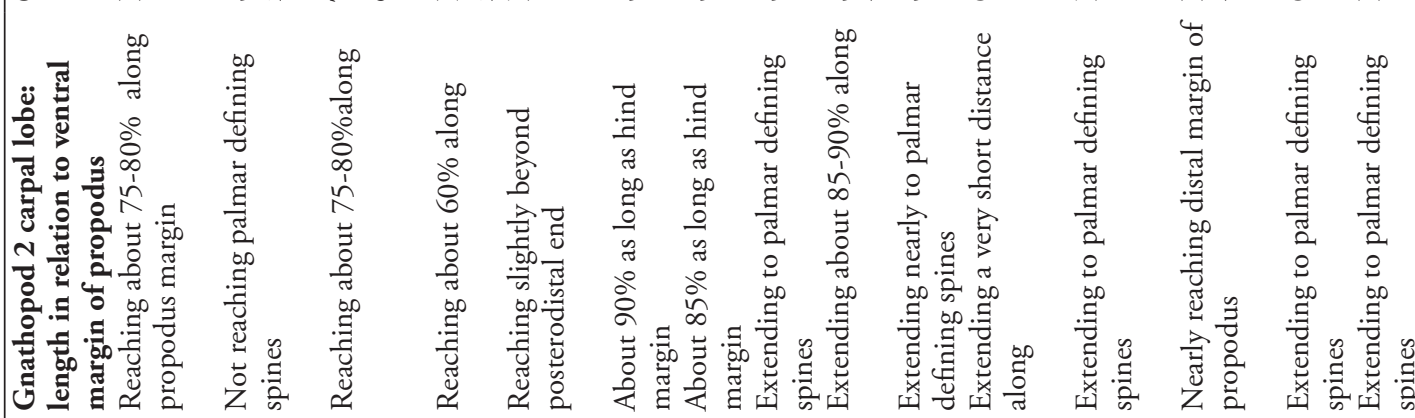

咅离

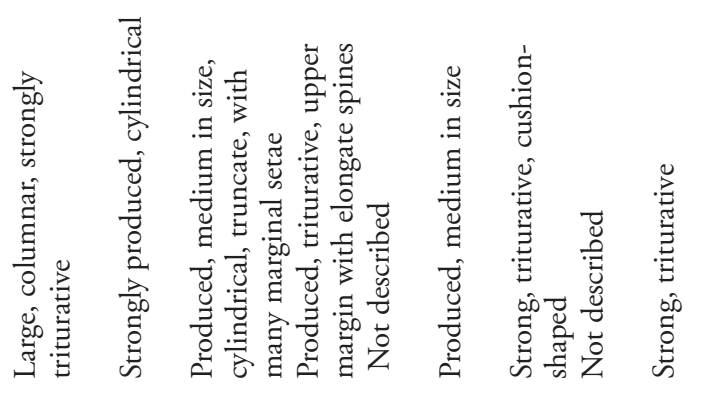
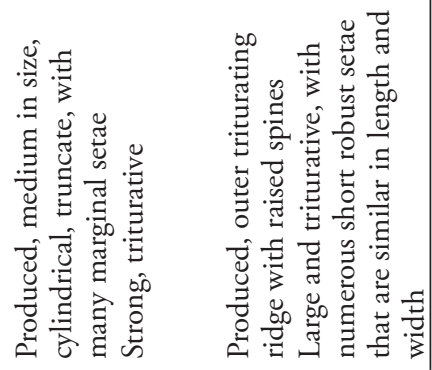

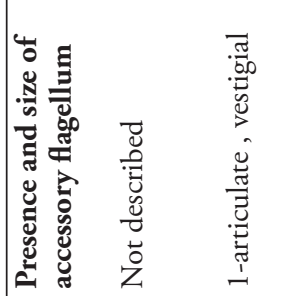

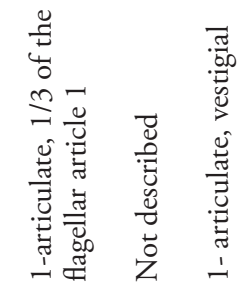
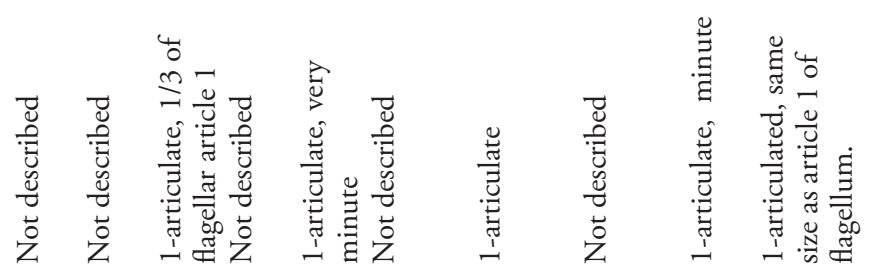

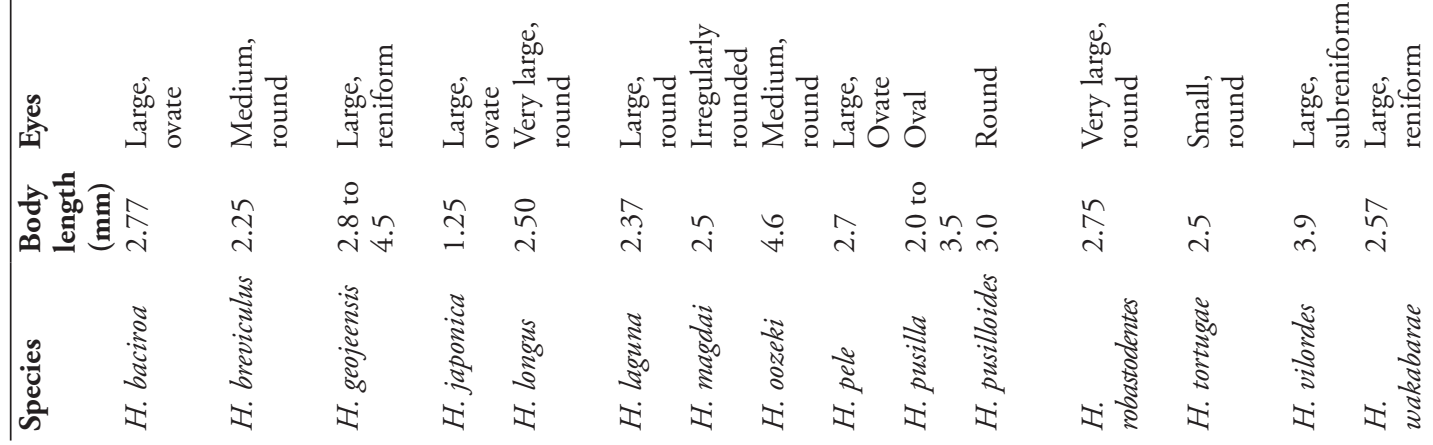


ACKNOWLedgements - We thank FAPESP (Process No. 1998/07090-3) for partly funding this study. The authors are very grateful to Simone Aparecida Dena Silva, who helped prepare the drawings and to the contribution of anonymous reviewers.

\section{REFERENCES}

Baldinger, A.J.; Gable M.F. and Lazo-Wasem, E.A. 2002. The Amphilochidae (Crustacea: Amphipoda) of Bermuda. Fourth European Crustacean Conference. http://www.yale.edu/inverts/caribs/lochcop3.pdf

Bousfield, E.L. 1979. A revised classification and phylogeny of amphipod crustaceans. Transactions of the Royal Society of Canada, Series 4(16): 343-390.

Coleman, C.O. 2003. "Digital inking". How to make perfect line drawings on computers? Organisms, Diversity and Evolution, 3(14): 1-14.

Della Valle, A. 1893. Gammarini del Golfo di Napoli. Fauna und Flora des Golfes von Neapel, 20: 1-948.

Kim, C.B. and Kim, W. 1992. A new species of the genus Gitanopsis (Amphipoda, Amphilochidae) from Korea. The Korean Journal of Systematic Zoology, 8(2): 183-188.

Kim, Y-H.; Hendrycks, E.A. and Lee, K-S. 2010. A new species and new record of the Amphilochidae (Crustacea: Amphipoda) from Korea. Zootaxa, 2477: 21-36.

Hirayama, A. and Takeuchi, I. 1993. New species and new Japanese records of the Gammaridea (Crustacea: Amphipoda) from Matsukawa-ura Inlet, Fukushima Prefecture, Japan. Publications of the Seto Marine Biological Laboratory, 36(3): 141-178.

Hoover, P.M. and Bousfield, E.L. 2001. The amphipod superfamily Leucothoidea on the Pacific coast of North America: family Amphilochidae: systematics and distributional ecology. Amphipacifica, 3: 3-28.

Leite, F.P.P. 1996. Alteraçóes morfológicas dos estádios de crescimento de Amphilocus neapolitanus Della Valle, 1893 (Gammaridea, Amphilochidae) e Ampithoe ramondi Audouin, 1826 (Gammaridea, Ampithoidae) anfípodes associados à alga Sargassum cymosum. Revista Brasileira de Zoologia, 13(1): 47 60.

Leite, F.P.P. 2002. Life cycle observations on Amphilocus neapolitanus (Della Valle, 1853) (Crustacea, Amphipoda) associated with Sargassum cymosum C. Agardh, 1820 in Ubatuba, (SP), Brazil. Brazilian Archives of Biology and Technology, 45(3): 355-363.

McKinney, L.D. 1978. Amphilochidae (Crustacea: Amphipoda) from the western Gulf of Mexico and Caribbean Sea. Gulf Research Reports, 6(2): 137-143.

Ortíz, M. and Lalana, R. 1996. Gitanopsis templadoi, una nueva especie de anfípodo (Gammaridea, Amphilochidae), de la plataforma suroccidental de Cuba. Anales del Instituto de Ciencias del Mary Limnología, 22: 121-124.

Ortiz, M.; Martín, A. and Diaz, Y.J. 2007. Lista y referencia de los crustáceos anfípodos (Amphipoda: Gammaridea) del Atlántico occidental tropical. Revista de Biología Tropical, 55(2): 479-498.

Schellenberg, A. 1938. Brazilianische Amphipoden, mit biologischen Bemerkungen. Zoologische Jahrbücher, Systematik, Ökologie und Geographie der Tiere, 71: 203218.

Serejo, C.S. 1998. Gammaridean and caprellidean fauna (Crustacea) associated with the sponge Dysidea fragilis Johnston at Arraial do Cabo, Rio de Janeiro, Brazil. Bulletin of Marine Science, 63(2): 363-385.
Wakabara, Y.; Tararam, A.S. and Takeda, A.M. 1983. Comparative study of the amphipod fauna living on Sargassum of two Itanhaem shores, Brazil. Journal of Crustacean Biology, 3(4): 602-607.

Wakabara, Y. and Serejo, C.S. 1998. Malacostraca - Peracarida. Amphipoda. Gammaridea and Caprellidea. p. 561-594. In: Young, P.S. (ed): Catalogue of Crustacea of Brazil. Rio de Janeiro, Museu Nacional, Série Livros, no. 6.

Wakabara, Y.; Tararam, A.S.; Valério-Berardo, M.T.; Duleba, W. and Leite, F.P.P. 1991. Gammaridean and caprellidean fauna from Brazil. Hydrobiologia, 223(1): 69-77.

Watling, L. 1989. A classification of crustacean setae based on the homology concept. p. 15-26. In: Felgenhauer, B.E.; Thistle, A.B. and Watling, L. (eds), Crustacean Issues. Vol. 6. Functional Morphology of Feeding and Grooming in Crustacea. Rotterdam, A.A. Balkema. 